\title{
(6) OPEN ACCESS \\ Two-year trends and predictors of e-cigarette use in 27 European Union member states
}

\author{
Filippos T Filippidis, ${ }^{1}$ Anthony A Laverty, ${ }^{1}$ Vasiliki Gerovasili, ${ }^{2}$ Constantine I Vardavas ${ }^{3}$
}

\begin{abstract}
- Additional material is published online only. To view please visit the journal online (http://dx.doi.org/10.1136/ tobaccocontrol-2015-052771).

1 Department of Primary Care and Public Health, School of Public Health, Imperial College London, London, UK

${ }^{2}$ Department of Ergospirometry and Rehabilitation, Medical School, University of Athens, Athens, Greece

${ }^{3}$ Clinic of Social and Family Medicine, School of Medicine, University of Crete, Heraklion, Greece
\end{abstract}

\section{Correspondence to} Dr Filippos T Filippidis, School of Public Health, Imperial College London, 310 The Reynolds Building, St Dunstan's Road, London W6 8RP, UK;

f.filippidis@imperial.ac.uk

Received 16 October 2015 Revised 3 February 2016 Accepted 5 February 2016 Published Online First 24 May 2016

\section{CrossMark}

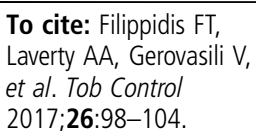

To cite: Filippidis FT, Laverty AA, Gerovasili V, et al. Tob Control 2017:26:98-104.

\section{ABSTRACT}

Objective This study assessed changes in levels of ever use, perceptions of harm from e-cigarettes and sociodemographic correlates of use among European Union (EU) adults during 2012-2014, as well as determinants of current use in 2014.

Methods We analysed data from the $2012(n=26751)$ and 2014 ( $n=26$ 792) waves of the adult Special Eurobarometer for Tobacco survey. Point prevalence of current and ever use was calculated and logistic regression assessed correlates of current use and changes in ever use, and perception of harm. Correlates examined included age, gender, tobacco smoking, education, area of residence, difficulties in paying bills and reasons for trying an e-cigarette.

Results The prevalence of ever use of e-cigarettes increased from $7.2 \%$ in 2012 to $11.6 \%$ in 2014 (adjusted OR (aOR)=1.91). EU-wide coefficient of variation in ever e-cigarette use was $42.1 \%$ in 2012 and $33.4 \%$ in 2014. The perception that e-cigarettes are harmful increased from $27.1 \%$ in 2012 to $51.6 \%$ in $2014(\mathrm{aOR}=2.99)$, but there were major differences in prevalence and trends between member states. Among those who reported that they had ever tried an e-cigarette in the 2014 survey, $15.3 \%$ defined themselves as current users. Those who tried an e-cigarette to quit smoking were more likely to be current users ( $\mathrm{aOR}=2.82$ ).

Conclusions Ever use of e-cigarettes increased during 2012-2014. People who started using e-cigarettes to quit smoking tobacco were more likely to be current users, but the trends vary by country. These findings underscore the need for more research into factors influencing e-cigarette use and its potential benefits and harms.

\section{INTRODUCTION}

Uncertainty surrounds the potential population health impacts of electronic cigarettes (e-cigarettes), and the issue has been dubbed one of the great debates in public health of our time. ${ }^{1}$ Research based on internet searches of available brands has indicated substantial growth in the availability of ecigarettes in recent years, ${ }^{2}$ which has further increased concern. Much of the controversy has centred on the degree to which the devices are a 'gateway' to smoking cigarettes, their role in renormalising cigarette smoking and their effectiveness in promoting quit attempts. ${ }^{3}$ Concern has also focused on variations in potential toxicity of differing brands, linked to a lack of regulation of their manufacture. ${ }^{4}$ The lack of certainty over these issues has been coupled with calls for regulation at a variety of levels until these issues can be settled. ${ }^{5}$
The European Union (EU) Tobacco Products Directive was passed in 2014 and will be implemented in 2016. Article 20 of the Directive has brought forward specific regulations with regard to the reporting of ingredients, emissions, quality control in production and potential design parameters that could mitigate risk. ${ }^{6}$ Nonetheless, the debate on other policy decisions, such as bans on advertising and use of e-cigarettes in public places or their use as cessation aids, is expected to intensify in coming years. Hence, up-to-date data on the prevalence of e-cigarette use are urgently needed in order to inform policy at a national and at a European level. ${ }^{7}$ Similarly, as more information on e-cigarettes becomes available, people's perceptions of their safety may change, which may impact use, as well as attitudes towards regulatory measures, for example, while rates of experimentation with ecigarettes have been found to be high in a number of settings, ${ }^{8}$ the evidence is less clear on the proportion of experimenters who go on to become regular users. ${ }^{9}$ Reasons for use of these products and how these may affect transition to regular use are additional areas of uncertainty. It is also worth investigating whether e-cigarettes are becoming more popular in younger age groups or among non-smokers in particular, as such a finding could potentially support calls for more strict regulation.

Previous analyses of EU-wide data in 2012 have assessed the prevalence of e-cigarette use, the relationship between tobacco and e-cigarette use, ${ }^{10}$ as well as sociodemographic variation in e-cigarette use. ${ }^{11}$ However, the landscape in regard to e-cigarettes is changing constantly. Therefore, the aim of the current study was to assess changes in e-cigarette ever use and in perceptions of its harmfulness, between 2012 and 2014, within 27 EU member states, as well as to explore associations of regular use with sociodemographic factors and reasons for use.

\section{METHODS}

\section{Data source}

We conducted a secondary analysis of data collected in two Eurobarometer surveys, wave 77.1 (February-March 2012) and wave 82.4 (November-December 2014). ${ }^{12}{ }^{13}$ Eurobarometer surveys are funded by the European Commission. A similar multistage probability sampling design was followed in each EU member state in both waves. Primary sampling units (PSU) were selected from each regional unit of each country, proportional to population size. A sample of starting addresses was randomly selected in each PSU, and households were systematically selected following a standard random route starting from these initial 
addresses. Following the collection of the data, poststratification and population size weighting were applied in each country/ region using Eurostat data on gender, age and area of residence, resulting in nationally representative samples in terms of age, gender and area of residence. A total of $n=26751$ individuals aged $\geq 15$ years from $27 \mathrm{EU}$ member states, and $\mathrm{n}=27801$, aged $\geq 15$ years, from $28 \mathrm{EU}$ member states (including Croatia), were interviewed in 2012 and 2014, respectively. However, since Croatia was not included in the 2012 wave, it was excluded from the analysis; therefore the total sample size in 2014 was $n=26792$ (see online supplementary table S1). Interviews were conducted in people's homes and in the language of the respective country.

\section{Measures}

E-cigarette use

In 2012, the use of e-cigarettes was assessed within the Eurobarometer with the question: 'Have you ever tried any of the following products? Electronic cigarettes...'; and responses included: 'Yes, you use or used it regularly'; 'Yes, you use or used it occasionally'; 'Yes, you tried it once or twice'; 'No'; and 'Don't know'. In 2014, the question was modified as follows: 'Regarding the use of electronic cigarettes or any similar electronic devices (e-shisha, e-pipe), which of the following statements applies to you?'; and responses included: 'You currently use electronic cigarettes or similar electronic devices (eg, e-shisha, e-pipe)'; 'You used them in the past, but no longer use them'; 'You tried them in the past but no longer use them'; 'You have never used them'; and 'Don't know'.

For the comparison between waves, all the respondents who reported that they had ever used or tried e-cigarettes were classified as 'ever users of e-cigarettes'. Among e-cigarette ever users (2014 survey only), respondents who said that they were currently using electronic cigarettes were classified as current e-cigarette users and the rest as former e-cigarette users.

\section{Reasons for e-cigarette use}

In wave 82.4 (2014), respondents who had ever tried e-cigarettes were also asked 'How important was each of the following factors for starting (e-cigarettes)? 1. To be able to smoke in places where tobacco smoking is not allowed; 2. To stop or reduce tobacco smoking; 3 . You considered them attractive, cool or fashionable'. For each factor, respondents could either say it was important ('very important'; 'fairly important'); not important ('not very important'; 'not at all important'); or "don't know".

\section{Perception of harmfulness}

Perception of e-cigarette harmfulness was assessed in both waves with the question 'In recent years, electronic cigarettes, or e-cigarettes, have been increasingly marketed in Europe. Do you think that they are harmful or not to the health of those who use them?'. Participants could respond 'yes'; 'no'; and 'don't know'; for our analysis, 'no' and 'don't know' were grouped together.

\section{Current tobacco use}

Smoking status was assessed with the question "Regarding smoking cigarettes, cigars or a pipe, which of the following applies to you?". Individuals who chose the response "You currently smoke" were classified as current smokers, those who selected the response 'You used to smoke but you have stopped' were classified as former smokers and those who responded that 'they have never smoked' were classified as never smokers.
Sociodemographic characteristics

Data were collected on participants' age $(15-24 ; 25-39 ; 40-54$; and $\geq 55$ years), gender (male; female), educational level (the age when they stopped full-time education: $\leq 15 ; 16-19$ or $\geq 20$ years of age) and area of residence (rural; urban). Financial difficulties, as a potential proxy for socioeconomic status, were assessed with the question 'During the last twelve months, would you say you had difficulties to pay your bills at the end of the month...?' Response options included: 'Most of the time', 'From time to time' or 'Almost never/never'; for the purpose of this analysis, 'Most of the time' and 'From time to time' were grouped together.

\section{Statistical analysis}

Descriptive results are presented as proportions (\%) with 95\% CIs, while logistic regression results are presented as adjusted ORs (aOR) with 95\% CI. Results are presented by geographic region, according to the United Nations geoscheme. ${ }^{14}$ Changes in ever use and perceptions of harmfulness in each country, between 2012 and 2014, were assessed with logistic regression models, adjusted for age and smoking status, as these two were the most important factors associated with e-cigarette use in the 2012 wave. $^{10}$ The EU-wide dispersion in ever e-cigarette use and perception of harm was determined using the coefficient of variation, computed as the ratio of the $\mathrm{SD}$ to the mean.

In order to explore changes in ever use of e-cigarettes and perceptions between 2012 and 2014 in the EU, a logistic regression model was fitted with survey year as an independent variable, adjusted for: age; educational level; difficulty to pay bills; gender; area of residence and smoking status. In order to assess differences in trends, two-way interaction terms between the survey year and age, and between survey year and smoking status, were initially included in the model; however, none of these was statistically significant and they were dropped from the final model. A separate multilevel logistic regression was fitted among respondents who had ever tried e-cigarettes (2014 survey only), where being a current e-cigarette user was the outcome and independent variables included: age; educational level; difficulty to pay bills; gender; area of residence; smoking status; and reasons for trying e-cigarettes. 'Reasons for trying e-cigarettes' was added to the model in a stepwise forward method, as these may be considered as mediating factors between the association of sociodemographic factors and smoking; the significance level to keep variables in the model was set to 0.10 . Finally, we calculated the Pearson correlation coefficient between the prevalence of ever smokers (current and former smokers) and the prevalence of e-cigarette ever use at a country level, in 2014, in order to explore whether variation in ever use of e-cigarettes could be explained by differences in the prevalence of current and former smoking.

All analyses were performed with Stata 12.0 and weights provided in the official Eurobarometer datasets were used in order to account for the complex design of the survey.

\section{RESULTS}

\section{E-cigarette use}

Ever use of an e-cigarette in all $27 \mathrm{EU}$ member states increased from $7.2 \%$ (95\% CI $6.7 \%$ to $7.7 \%$ ) in 2012 to $11.6 \%$ (95\% CI $10.9 \%$ to $12.3 \%$ ) in 2014 . EU-wide coefficient of variation in ever e-cigarette use was $42.1 \%$ in 2012 and $33.4 \%$ in 2014. Ever use of e-cigarettes in the 2014 survey varied widely between countries, ranging from $5.7 \%$ in Portugal to $21.3 \%$ in France. The Pearson correlation coefficient between the 
prevalence of ever smokers and the prevalence of e-cigarette ever use at a country level was 0.28 , indicating some correlation between the two variables. Similarly, several EU member states, such as Malta $(\mathrm{aOR}=5.46 ; 95 \%$ CI 2.82 to 10.58), showed considerable increase in the odds of ever e-cigarette use, whereas in some countries, the odds of ever e-cigarette use did not change significantly between 2012 and 2014. Also, within the 2014 Eurobarometer survey, approximately one in seven respondents who had ever tried an e-cigarette defined themselves as current e-cigarette users-indicating a transition from experimentation to current use $(15.3 \%$; $95 \%$ CI $12.9 \%$ to $17.7 \%$ ), with between-EU member state variation ranging from $1.7 \%$ in Slovenia to $28.9 \%$ in Portugal (table 1).

\section{Perception of harmfulness}

The proportion of respondents who thought that e-cigarettes are harmful increased from $27.1 \%$ (95\% CI $26.3 \%$ to $28.0 \%$ ) in 2012 to $51.6 \%$ (95\% CI $50.6 \%$ to $52.5 \%$ ) in 2014 , in the EU. In the 2014 survey, there was considerable variation between EU member states regarding the perceived harmfulness of e-cigarettes, with coefficient variation $=19.2 \%$ (compared to $36.1 \%$ in 2012), and prevalence ranged from $31.1 \%$ in Hungary to $78.1 \%$ in the Netherlands. However, in most European countries, with the exception of Greece and Hungary, where the increase was not statistically significant, the perception that e-cigarettes are harmful increased significantly between 2012 and 2014 (table 2).

\section{Factors associated with e-cigarette use}

After adjusting for tobacco smoking and sociodemographic factors, respondents were more likely to report that they had tried an e-cigarette in 2014, compared to 2012 (aOR $=1.90$; 95\% CI 1.77 to 2.03 ) (table 3). Being a current or a former smoker significantly increased the likelihood of having ever tried an e-cigarette $(\mathrm{aOR}=23.36$; 95\% CI 20.86 to 26.17, and $\mathrm{aOR}=6.54 ; 95 \%$ CI 5.74 to 7.45 , respectively). Also, younger age (especially being 18-24 years old), living in urban areas and higher educational level, were associated with higher likelihood of having ever tried an e-cigarette. Respondents were also more likely to regard e-cigarettes as being harmful in 2014

Table 1 Changes in ever use of e-cigarettes and percentage of ever users who transitioned to current use in 27 European Union member states, 2012-2014

\begin{tabular}{|c|c|c|c|c|}
\hline \multirow[b]{2}{*}{ Country } & \multicolumn{3}{|c|}{ Ever tried e-cigarettes } & \multirow{2}{*}{$\begin{array}{l}\text { Ever users who transitioned to } \\
\text { current users } 2014 t \\
\%(95 \% \mathrm{Cl})\end{array}$} \\
\hline & $\begin{array}{l}2012 \\
\%(95 \% \mathrm{Cl})\end{array}$ & $\begin{array}{l}2014 \\
\%(95 \% \mathrm{Cl})\end{array}$ & $\begin{array}{l}\text { Change during 2012-2014 } \\
\text { aOR }(95 \% \mathrm{Cl})^{*}\end{array}$ & \\
\hline \multicolumn{5}{|l|}{ Southern Europe } \\
\hline Cyprus & 7.5 (5.2 to 9.8$)$ & 16.7 (12.8 to 20.6$)$ & 3.33 (1.97 to 5.63$)$ & 11.2 (3.4 to 19$)$ \\
\hline Greece & 10.6 (8.6 to 12.5$)$ & 8.2 (6.5 to 9.9) & 0.80 (0.58 to 1.11$)$ & $10.6(4.2$ to 17$)$ \\
\hline Italy & 3.9 (2.7 to 5.2$)$ & 8.2 (6.3 to 10.0$)$ & 2.52 (1.62 to 3.92 ) & $5.4(0.1$ to 10.7$)$ \\
\hline Malta & 4.8 (2.6 to 6.9$)$ & $12.6(9.0$ to 16.3$)$ & $5.46(2.82$ to 10.58$)$ & $1.8(0.0$ to 5.3$)$ \\
\hline Portugal & 4.5 (3.1 to 5.8$)$ & 5.7 (4.2 to 7.2$)$ & 1.49 (0.94 to 2.34$)$ & 28.9 (16.2 to 41.5$)$ \\
\hline Slovenia & 7.1 (5.4 to 8.8 ) & 6.7 (4.8 to 8.6 ) & 0.87 (0.57 to 1.32 ) & $1.7(0.0$ to 5.0$)$ \\
\hline Spain & 4.6 (3.3 to 5.9$)$ & 8.5 (6.6 to 10.3$)$ & 2.55 (1.69 to 3.85 ) & $6.0(0.8$ to 11.3$)$ \\
\hline \multicolumn{5}{|l|}{ Western Europe } \\
\hline Austria & 6.2 (4.7 to 7.7$)$ & 8.9 (7.0 to 10.8$)$ & 1.99 (1.37 to 2.90$)$ & 14.7 (5.8 to 23.7 ) \\
\hline Belgium & 4.1 (2.8 to 5.3$)$ & 9.0 (6.9 to 11.2$)$ & 2.88 (1.80 to 4.62$)$ & 6.3 (1.1 to 11.5$)$ \\
\hline France & 7.3 (5.7 to 9.0 ) & 21.3 (18.3 to 24.3$)$ & 4.30 (3.00 to 6.18 ) & 18.9 (12.6 to 25.2$)$ \\
\hline Germany & 6.6 (5.1 to 8.1) & 7.5 (6.0 to 9.1$)$ & 1.23 (0.86 to 1.77 ) & 17.2 (8.4 to 26.0$)$ \\
\hline Luxembourg & 8.6 (5.9 to 11.4$)$ & 12.3 (8.6 to 15.9$)$ & 2.12 (1.19 to 3.78 ) & 11.5 (2.5 to 20.4$)$ \\
\hline The Netherlands & 6.3 (4.6 to 8.0$)$ & 10.3 (8.1 to 12.4$)$ & 2.09 (1.38 to 3.18$)$ & 18.1 (9.8 to 26.5$)$ \\
\hline \multicolumn{5}{|l|}{ Northern Europe } \\
\hline Denmark & 13.1 (10.9 to 15.4$)$ & 15.8 (13.3 to 18.4$)$ & 1.60 (1.15 to 2.23$)$ & 13.8 (8.4 to 19.2 ) \\
\hline Estonia & $10.0(7.9$ to 12.1$)$ & $15.2(12.4$ to 17.9$)$ & 2.48 (1.71 to 3.59$)$ & 6.4 (2.0 to 10.8$)$ \\
\hline Finland & 7.4 (5.1 to 9.7) & 13.2 (10.7 to 15.7$)$ & 2.80 (1.75 to 4.49 ) & 9.5 (3.7 to 15.4$)$ \\
\hline Ireland & 4.4 (3 to 5.7 ) & 12.2 (10.0 to 14.4$)$ & 5.13 (3.35 to 7.85$)$ & 23.2 (15.3 to 31.0$)$ \\
\hline Latvia & 11.8 (9.7 to 13.8$)$ & 15.0 (12.4 to 17.7$)$ & 1.90 (1.37 to 2.63$)$ & $5.6(0.5$ to 10.7$)$ \\
\hline Lithuania & 5.0 (3.6 to 6.4$)$ & 10.0 (7.7 to 12.2$)$ & 2.83 (1.84 to 4.35$)$ & $4.4(0.0$ to 9.3$)$ \\
\hline Sweden & 2.1 (1.1 to 3.1$)$ & $7.9(5.8$ to 10.0$)$ & 4.48 (2.47 to 8.10$)$ & $3.9(0.0$ to 7.9$)$ \\
\hline UK & 8.9 (7.0 to 10.8$)$ & 15.5 (12.9 to 18.0$)$ & 3.09 (2.16 to 4.44$)$ & 26.5 (18.7 to 34.2 ) \\
\hline \multicolumn{5}{|l|}{ Eastern Europe } \\
\hline Bulgaria & 13.9 (11.6 to 16.1$)$ & 11.5 (9.5 to 13.5$)$ & $0.83(0.62$ to 1.12$)$ & $9.3(4.0$ to 14.6$)$ \\
\hline Czech Republic & $11.6(9.5$ to 13.7$)$ & $14.9(12.6$ to 17.3$)$ & 1.79 (1.29 to 2.47$)$ & $7.6(3.2$ to 12.1$)$ \\
\hline Hungary & 8.8 (7.0 to 10.6$)$ & $8.0(6.2$ to 9.8$)$ & 0.97 (0.68 to 1.37 ) & $5.6(0.7$ to 10.4$)$ \\
\hline Poland & 12.4 (10.1 to 14.6$)$ & 14.6 (12.3 to 16.9$)$ & 1.49 (1.10 to 2.03$)$ & $13.2(7.3$ to 19.1$)$ \\
\hline Romania & 8.0 (6.3 to 9.7$)$ & 8.8 (7.0 to 10.6$)$ & 1.22 (0.85 to 1.74$)$ & $5.2(0.0$ to 10.3$)$ \\
\hline Slovakia & 3.2 (2.1 to 4.4$)$ & 6.7 (5.0 to 8.4$)$ & 2.86 (1.76 to 4.65$)$ & $7.6(0.8$ to 14.5$)$ \\
\hline 27 EU states & 7.2 (6.7 to 7.7$)$ & 11.6 (10.9 to 12.3$)$ & 1.91 (1.79 to 2.05$)$ & 15.3 (12.9 to 17.7$)$ \\
\hline
\end{tabular}


Table 2 Changes in perception of harm from e-cigarettes in 27 European Union member states, 2012-2014

\begin{tabular}{|c|c|c|c|}
\hline \multirow[b]{2}{*}{ Country } & \multicolumn{3}{|c|}{ Perceiving e-cigarettes as harmful \% } \\
\hline & $\begin{array}{l}2012 \\
\%(95 \% \mathrm{Cl})\end{array}$ & $\begin{array}{l}2014 \\
\%(95 \% \mathrm{Cl})\end{array}$ & $\begin{array}{l}\text { Change during } \\
2012-2014 \\
\text { aOR }(95 \% \mathrm{Cl})^{*}\end{array}$ \\
\hline \multicolumn{4}{|c|}{ Southern Europe } \\
\hline Cyprus & 23.6 (19.9 to 27.3 ) & 62.8 (58.2 to 67.4$)$ & 5.64 (4.20 to 7.56$)$ \\
\hline Greece & 49.0 (45.8 to 52.2 ) & 53.1 (49.9 to 56.4$)$ & 1.19 (0.98 to 1.42$)$ \\
\hline Italy & $13.9(11.8$ to 16.1$)$ & 41.3 (38.1 to 44.6$)$ & 4.33 (3.47 to 5.42$)$ \\
\hline Malta & 23.8 (19.5 to 28.2$)$ & $63.2(58.5$ to 67.9$)$ & $5.48(4.00$ to 7.51$)$ \\
\hline Portugal & 26.5 (23.8 to 29.3 ) & $57.1(53.9$ to 60.3$)$ & 4.07 (3.33 to 4.98$)$ \\
\hline Slovenia & 34.3 (31.3 to 37.3 ) & 59.8 (56.5 to 63.0$)$ & 2.85 (2.36 to 3.45$)$ \\
\hline Spain & $14.7(12.5$ to 17.0$)$ & 55.7 (52.5 to 58.8$)$ & 7.34 (5.90 to 9.14$)$ \\
\hline \multicolumn{4}{|c|}{ Western Europe } \\
\hline Austria & 27.1 (24.3 to 30.0$)$ & 42.3 (38.7 to 45.9$)$ & 2.06 (1.67 to 2.54$)$ \\
\hline Belgium & 35.8 (32.8 to 38.8 ) & 52.9 (49.5 to 56.2$)$ & 2.02 (1.68 to 2.44$)$ \\
\hline France & 25.8 (23.0 to 28.5 ) & 59.9 (56.4 to 63.4$)$ & 4.35 (3.54 to 5.35$)$ \\
\hline Germany & $46.2(43.3$ to 49.1$)$ & $51.2(48.4$ to 54.1$)$ & 1.25 (1.06 to 1.47$)$ \\
\hline Luxembourg & 39.1 (34.6 to 43.6$)$ & $66.0(61.1$ to 70.8$)$ & 3.01 (2.25 to 4.03$)$ \\
\hline $\begin{array}{l}\text { The } \\
\text { Netherlands }\end{array}$ & 41.6 (38.3 to 44.9$)$ & 78.1 (75.3 to 80.9$)$ & 5.21 (4.19 to 6.49$)$ \\
\hline \multicolumn{4}{|c|}{ Northern Europe } \\
\hline Denmark & $28.2(25.3$ to 31.1$)$ & $69.4(66.4$ to 72.5$)$ & $6.02(4.90$ to 7.40$)$ \\
\hline Estonia & 37.5 (34.4 to 40.7$)$ & 67.1 (63.9 to 70.4$)$ & 3.63 (2.96 to 4.46$)$ \\
\hline Finland & 52.9 (48.9 to 56.9$)$ & 70.4 (67.3 to 73.4$)$ & 2.08 (1.67 to 2.59$)$ \\
\hline Ireland & 12.5 (10.4 to 14.7$)$ & 47.5 (44.3 to 50.7 ) & 6.56 (5.19 to 8.31$)$ \\
\hline Latvia & 51.6 (48.5 to 54.7 ) & 63.5 (60.1 to 66.8$)$ & 1.66 (1.36 to 2.01$)$ \\
\hline Lithuania & 29.5 (26.7 to 32.4 ) & 69.8 (66.8 to 72.9$)$ & 5.55 (4.53 to 6.80$)$ \\
\hline Sweden & 23.1 (20.0 to 26.2 ) & 67.6 (64.1 to 71.2$)$ & 7.18 (5.65 to 9.13$)$ \\
\hline UK & 15.2 (12.9 to 17.5$)$ & 38.4 (35.1 to 41.6$)$ & 3.49 (2.78 to 4.39$)$ \\
\hline \multicolumn{4}{|c|}{ Eastern Europe } \\
\hline Bulgaria & 20.4 (17.8 to 23.0$)$ & 45.5 (42.3 to 48.6 ) & 3.28 (2.67 to 4.02$)$ \\
\hline $\begin{array}{l}\text { Czech } \\
\text { Republic }\end{array}$ & 30.0 (27.1 to 33.0$)$ & 54.3 (51.1 to 57.5$)$ & 2.79 (2.31 to 3.38$)$ \\
\hline Hungary & 31.1 (28.2 to 34.0$)$ & 32.6 (29.6 to 35.5 ) & $1.10(0.91$ to 1.33$)$ \\
\hline Poland & 25.7 (22.8 to 28.5 ) & 52.1 (49.0 to 55.3$)$ & 3.39 (2.78 to 4.14$)$ \\
\hline Romania & 32.6 (29.6 to 35.5 ) & 54.3 (51.1 to 57.4 ) & 2.53 (2.10 to 3.05$)$ \\
\hline Slovakia & 27.9 (24.9 to 30.9 ) & 47.8 (44.6 to 51.1 ) & 2.38 (1.95 to 2.90$)$ \\
\hline 27 EU states & 27.1 (26.3 to 28.0 ) & 51.6 (50.6 to 52.5 ) & 2.99 (2.89 to 3.10$)$ \\
\hline
\end{tabular}

$(\mathrm{aOR}=2.98 ; 95 \%$ CI 2.87 to 3.09$)$, while those who were younger, had a higher educational level, less financial difficulties and who were former smokers, were more likely to perceive e-cigarettes as harmful (table 3 ).

All two-way interaction terms between survey year and the other variables were not significant, indicating that the increase in the odds of having tried e-cigarettes between 2012 and 2014 did not significantly differ between men and women; between current smokers, former smokers and never smokers; and so on.

Among those who had ever tried an e-cigarette, those defining themselves as current e-cigarette users were more likely to be older. Current e-cigarette users were more likely to have started using e-cigarettes because they thought e-cigarettes could help them quit smoking $(\mathrm{aOR}=2.82 ; 95 \% \mathrm{CI} 1.99$ to 3.99$)$, as well as to circumvent smoking bans $(\mathrm{aOR}=1.54$; 95\% CI 1.19 to 2.00). On the contrary, attractiveness did not seem to influence their decision to become regular e-cigarette users $(\mathrm{aOR}=0.74$; 95\% CI 0.53 to 1.02 ) (table 4).
Table 3 Factors associated with having ever used an e-cigarette, and perception of harm in 27 European Union member states, 2012-2014

\begin{tabular}{|c|c|c|}
\hline & $\begin{array}{l}\text { Having ever used } \\
\text { e-cigarettes aOR } \\
(95 \% \mathrm{Cl})\end{array}$ & $\begin{array}{l}\text { Perceiving } \\
\text { e-cigarettes as } \\
\text { harmful aOR } \\
(95 \% \mathrm{Cl})\end{array}$ \\
\hline \multicolumn{3}{|l|}{ Survey year } \\
\hline 2012 (ref) & 1.00 & 1.00 \\
\hline 2014 & 1.90 (1.77 to 2.03$)$ & 2.98 (2.87 to 3.09$)$ \\
\hline \multicolumn{3}{|l|}{ Gender } \\
\hline Female (ref) & 1.00 & 1.00 \\
\hline Male & 1.14 (1.06 to 1.22$)$ & $0.94(0.91$ to 0.98$)$ \\
\hline \multicolumn{3}{|l|}{ Age (years) } \\
\hline$\geq 55$ (ref) & 1.00 & 1.00 \\
\hline $40-54$ & 2.03 (1.84 to 2.25$)$ & $1.08(1.03$ to 1.13$)$ \\
\hline $25-39$ & 3.16 (2.86 to 3.49$)$ & $1.17(1.11$ to 1.23$)$ \\
\hline $18-24$ & 5.75 (5.11 to 6.47$)$ & $1.34(1.25$ to 1.43$)$ \\
\hline \multicolumn{3}{|c|}{ Education (age at completion, years) } \\
\hline$\leq 15$ (ref) & 1.00 & 1.00 \\
\hline $16-19$ & 1.47 (1.30 to 1.66$)$ & $1.08(1.02$ to 1.14$)$ \\
\hline$\geq 20$ & 1.65 (1.45 to 1.88$)$ & $1.22(1.15$ to 1.29$)$ \\
\hline \multicolumn{3}{|l|}{ Area of residence } \\
\hline Rural & 1.00 & 1.00 \\
\hline Urban & 1.21 (1.12 to 1.31$)$ & $1.02(0.98$ to 1.06$)$ \\
\hline \multicolumn{3}{|l|}{ Difficulty in paying bills } \\
\hline Almost never/never (ref) & 1.00 & 1.00 \\
\hline $\begin{array}{l}\text { From time to time/most } \\
\text { of the time }\end{array}$ & 1.07 (0.99 to 1.16$)$ & $0.96(0.92$ to 1.00$)$ \\
\hline \multicolumn{3}{|l|}{ Smoking status } \\
\hline Never smoker (ref) & 1.00 & 1.00 \\
\hline Current smoker & 23.36 (20.86 to 26.17 ) & 1.00 (0.96 to 1.05$)$ \\
\hline Former smoker & 6.54 (5.74 to 7.45$)$ & $1.19(1.14$ to 1.25$)$ \\
\hline
\end{tabular}

\section{DISCUSSION}

This analysis of the most up-to-date data from the whole of the EU shows that although perceptions that e-cigarettes are harmful are increasing, levels of ever use are also increasing. Those who began using e-cigarettes as a means to quit tobacco smoking or who used them in order to circumvent smoking bans were more likely to be current users of e-cigarettes.

Interestingly, the proportion of youth and adults that reported having used e-cigarettes showed wide variation between European countries. These differences may be partly explained by the different prevalence of smoking in EU member states, considering that current and former smokers were much more likely to have tried e-cigarettes. This hypothesis is in line with the moderate correlation found between the prevalence of ever smokers and the prevalence of e-cigarette ever use at a country level. Moreover, use of e-cigarettes is also promoted as a cessation aid and this appears to be an important reason for many users. ${ }^{15}$ Thus, availability and access to cessation aids may have influenced the adoption of e-cigarettes. For example, in Greece and Bulgaria, where smoking prevalence is high and use of evidence-based cessation aids low, ${ }^{16}$ ever use of e-cigarettes was reported by more than $10 \%$ of the respondents in 2012 . Similarly, trends between 2012 and 2014 could have been influenced by a number of factors that might differ between member states. Such factors include affordability of cigarettes and e-cigarettes, regulation of advertising and promotional activities, 
Table 4 Factors associated with being a current e-cigarette user among those who have ever used e-cigarettes in 27 European Union member states, 2014 ( $n=2452)$

\begin{tabular}{|c|c|c|}
\hline & $\begin{array}{l}\text { Being a current } \\
\text { e-cigarette user } \\
\%(95 \% \mathrm{Cl})\end{array}$ & $\begin{array}{l}\text { Being a current } \\
\text { e-cigarette user } \\
\text { aOR }(95 \% \mathrm{Cl})\end{array}$ \\
\hline \multicolumn{3}{|l|}{ Gender } \\
\hline Female (ref) & $14.2(10.6$ to 17.7$)$ & 1.00 \\
\hline Male & 17.7 (14.1 to 21.3$)$ & 1.23 (0.95 to 1.58$)$ \\
\hline \multicolumn{3}{|l|}{ Age (years) } \\
\hline$\geq 55$ (ref) & 21.1 (15.5 to 26.6$)$ & 1.00 \\
\hline $40-54$ & 20.3 (14.9 to 25.7$)$ & $0.89(0.64$ to 1.25$)$ \\
\hline $25-39$ & 13.7 (9.4 to 18.1$)$ & $0.57(0.40$ to 0.81$)$ \\
\hline $18-24$ & $10.8(6.2$ to 15.5$)$ & $0.57(0.37$ to 0.88$)$ \\
\hline \multicolumn{3}{|c|}{ Education (age at completion, years) } \\
\hline$\leq 15$ (ref) & $22.2(14.4$ to 30.0$)$ & 1.00 \\
\hline $16-19$ & 16.4 (12.7 to 20.2$)$ & $0.85(0.56$ to 1.29$)$ \\
\hline$\geq 20$ & $13.8(10.0$ to 17.5$)$ & $0.74(0.47$ to 1.16$)$ \\
\hline \multicolumn{3}{|l|}{ Area of residence } \\
\hline Rural & $15.0(10.0$ to 20.0$)$ & 1.00 \\
\hline Urban & 16.5 (13.5 to 19.4$)$ & $1.02(0.77$ to 1.36$)$ \\
\hline \multicolumn{3}{|l|}{ Difficulty in paying bills } \\
\hline Almost never/never (ref) & 16.9 (13.5 to 20.4$)$ & 1.00 \\
\hline $\begin{array}{l}\text { From time to time/most } \\
\text { of the time }\end{array}$ & $14.9(11.2$ to 18.7$)$ & $0.95(0.72$ to 1.24$)$ \\
\hline \multicolumn{3}{|l|}{ Smoking status } \\
\hline Never smoker (ref) & 11.6 (5.2 to 17.9$)$ & 1.00 \\
\hline Current smoker & $14.1(11.3$ to 16.9$)$ & $0.72(0.43$ to 1.19$)$ \\
\hline Former smoker & 26.2 (18.7 to 33.6$)$ & $1.28(0.75$ to 2.20$)$ \\
\hline \multicolumn{3}{|c|}{ Reason to start: smoking bans } \\
\hline Not important & $14.2(10.8$ to 17.5$)$ & 1.00 \\
\hline Important & 18.4 (14.5 to 22.2$)$ & $1.54(1.19$ to 2.00$)$ \\
\hline \multicolumn{3}{|l|}{ Reason to start: cessation aid } \\
\hline Not important & 6.6 (3.8 to 9.4$)$ & 1.00 \\
\hline Important & 19.9 (16.6 to 23.2$)$ & 2.82 (1.99 to 3.99$)$ \\
\hline \multicolumn{3}{|l|}{ Reason to start: attractiveness } \\
\hline Not important & $16.2(13.3$ to 19.1$)$ & 1.00 \\
\hline Important & 15.6 (10.4 to 20.8$)$ & $0.74(0.53$ to 1.02$)$ \\
\hline
\end{tabular}

prevalence of use of other alternative tobacco products (eg, smokeless tobacco in Sweden) and enforcement of smoking bans in public places. In the majority of member states, the proportion of respondents who had tried e-cigarettes increased during the 2-year period between the surveys; most of the exceptions were countries where adoption of e-cigarettes was already high in 2012.

Similar to ever use of e-cigarettes, perception of harm and trends over time varied between countries, even though the overall proportion of the population that considered e-cigarettes as harmful almost doubled in 2 years. As e-cigarettes become more popular, more information becomes available and evidence on potential risks associated with its use is accumulated. ${ }^{17}$ Perceptions could also be influenced by public health campaigns, advertising and attitudes of health professionals and public health agencies towards e-cigarettes. For example, Public Health England recently published a report highlighting the potential of e-cigarettes as a harm reduction device, ${ }^{18}$ whereas most public health agencies in the EU have not done anything similar. Even though this report was published after the second wave of the survey, it might reflect a more favourable stance of authorities towards e-cigarettes in the UK, which may explain why it had one of the lowest proportions of respondents who perceive e-cigarettes as harmful.

Previous research has highlighted that the majority of e-cigarette use is among smokers ${ }^{7}{ }^{10}$ and that dual use is common. ${ }^{19} 20$ However, there are concerns that e-cigarettes could become popular among non-smokers and possibly serve as a gateway to cigarette smoking. Our analysis showed that non-smokers were much less likely to have ever tried an e-cigarette, compared to smokers; nevertheless, ever use of e-cigarettes increased among them as much as among smokers, between 2012 and 2014, raising concerns regarding their rising popularity in population groups not addicted to nicotine.

Our analysis also found that around one in seven people who had ever tried e-cigarettes defined themselves as current users. Many studies to date have failed to differentiate between experimentation and regular use, with the exception of some studies among young people. ${ }^{21}{ }^{22}$ Nonetheless, this one-in-seven figure is higher than reported in previous studies, which may reflect either differences by age or other factors. Additionally, despite its increasing popularity, those who tried an e-cigarette because they considered it attractive were not more likely to become current users, which may be in contrast to the importance of image and attractiveness for conventional cigarettes. $^{23}$ This may change as the market for e-cigarettes grows, and may depend on regulations around the advertising of these products.

People who started using e-cigarettes as a cessation aid were much more likely to be current users. The effectiveness of e-cigarettes as a cessation aid is still being researched, ${ }^{24}{ }^{25}$ but it seems that a proportion of smokers who are trying to quit may be using it as such. ${ }^{15}$ Dual use may also help smokers circumvent smoking bans by using e-cigarettes in places where tobacco smoking is prohibited, thus attenuating the impact of smoking bans. In the present study, those who thought that this was an important reason to try e-cigarettes were more likely to be current users-a possible indication of regular use. These findings may provide some insight into the motivation of people who become regular e-cigarette users and inform policies related to smoking cessation services and the effectiveness of smoking bans in public places.

Regarding perceptions of harm caused by e-cigarettes, evidence from the UK on 11-18-year-olds has similarly concluded that perceptions of harm are on the rise. ${ }^{7}$ We also found that perception that e-cigarettes are harmful was higher among respondents with higher education and financial status, findings that may indicate socioeconomic inequalities in knowledge about these novel products. However, as the discussion on the risks associated with e-cigarettes is ongoing, ${ }^{1}$ it would be interesting to explore how e-cigarette users and non-users perceive these risks in comparison to smoking. ${ }^{26}{ }^{27}$ It must be noted that almost 3 of 10 participants (29.1\%) responded that they did not know whether e-cigarettes were harmful, which indicates that there is still a lot of uncertainty regarding the health effects of ecigarettes. However, there is now evidence that e-cigarettes produce potentially harmful emissions, although the potential harms are most likely less than conventional cigarettes. ${ }^{17}$ Considering that e-cigarettes are sometimes promoted as 'healthier' alternatives to conventional cigarettes, it would be of more interest to assess whether people consider them equally or less harmful to cigarettes, but, unfortunately, no such data were collected in the Eurobarometer. Hence we decided to focus on people's awareness of potential harmfulness of e-cigarettes and grouped 'no' and 'don't know' reponses together. 


\section{Strengths and limitations}

This is the first study to assess the changes in perceptions and use of e-cigarettes in recent years, both nationally and at an EU level. The large sample size and the consistent sampling methodology allowed for reasonable comparisons between countries and years, despite all data being self-reported and no objective assessment of e-cigarette use being carried out. The wording of the questions assessing e-cigarette use was slightly different in 2014, not allowing us to assess changes in current use and potentially introducing misclassification bias. However, our analysis was limited to ever use of e-cigarettes and, despite the different wording between the two waves, there was no ambiguity in which response options reflected at least some use of e-cigarettes; therefore the bias introduced by this is most likely minimal. The question that assessed smoking status was somewhat atypical, but was consistent in both surveys. Moreover, any assumptions of causal relationships should be made with caution, as the data analysed were cross-sectional; longitudinal data would allow for more robust conclusions. Finally, current use was only assessed in 2014, and no data on important issues, such as duration of use and effectiveness as a cessation aid, were collected. ${ }^{28}$

\section{Conclusions}

Levels of ever use of e-cigarettes are increasing, and around one in seven of all people who have ever used e-cigarettes classify themselves as current users. These trends are against a backdrop of increasing perceptions that e-cigarettes are harmful to health, and there are large variations across the EU. Within these two consecutive cross sectional surveys, the majority of e-cigarette use is concentrated among current and former smokers, and people who start using e-cigarettes in order to quit smoking tobacco are more likely to continue to use e-cigarettes. These findings provide novel and extensive information on the prevalence and predictors of current use across the EU, and they highlight differences between member states. Further research in order to identify factors at individual and national level that may affect use of e-cigarettes is needed, ideally with prospective studies that could identify potential causal associations.

\section{What this paper adds}

- Ever use of e-cigarette in the European Union (EU) increased from $7.2 \%$ in 2012 to $11.6 \%$ in 2014 .

- EU residents were more likely to consider e-cigarettes as harmful in 2014 (51.6\%) than in 2012 (27.1\%).

- Those who started using e-cigarettes in order to quit smoking or circumvent smoking bans were more likely to become regular users.

- A better understanding of the population-level use and impact of e-cigarettes within the EU is needed, especially of the potential impact on smoke-free laws, smoking initiation and cessation.

\section{Twitter Follow Anthony Laverty at @anthonylav}

Acknowledgements The authors thank Dr Israel Agaku for his useful comments on the manuscript.

Contributors FTF had the main role in data analysis. FTF, AAL and VG had the main role in manuscript preparation. All the authors contributed to data interpretation and manuscript preparation. FTF is responsible for the overall content.
Funding This work was supported by a grant from the European Commission (Horizon2020 HCO-6-2015; EUREST-PLUS: 681109; Vardavas).

Competing interests None declared.

Provenance and peer review Not commissioned; externally peer reviewed.

Data sharing statement Eurobarometer datasets are publicly available online at http://zacat.gesis.org.

Open Access This is an Open Access article distributed in accordance with the Creative Commons Attribution Non Commercial (CC BY-NC 4.0) license, which permits others to distribute, remix, adapt, build upon this work non-commercially, and license their derivative works on different terms, provided the original work is properly cited and the use is non-commercial. See: http://creativecommons.org/ licenses/by-nc/4.0/

\section{REFERENCES}

1 Public Health England. E-cigarettes: an evidence update: a report commissioned by Public Health England. 2015. PHE publications gateway number: 2015260.

2 Zhu SH, Sun JY, Bonnevie E, et al. Four hundred and sixty brands of e-cigarettes and counting: implications for product regulation. Tob Control 2014;23(Suppl 3):iii3-9.

3 McKee M, Capewell S. Evidence about electronic cigarettes: a foundation built on rock or sand?, 2015;351:h4863.

4 Benowitz NL, Goniewicz ML. The regulatory challenge of electronic cigarettes. JAMA 2013;310:685-6.

5 Saitta D, Ferro GA, Polosa R. Achieving appropriate regulations for electronic cigarettes. Ther Adv Chronic Dis 2014;5:50-61.

6 Directive of the European Union on the approximation of the laws, regulations and administrative provisions of the Member States concerning the manufacture, presentation and sale of tobacco and related products and repealing Directive 2001/ 37/EC. http://ec.europa.eu/health/tobacco/docs/dir_201440_en.pdf (accessed 25th Sep 2015). Secondary Directive of the European Union on the approximation of the laws, regulations and administrative provisions of the Member States concerning the manufacture, presentation and sale of tobacco and related products and repealing Directive 2001/37/EC. http://ec.europa.eu/health/tobacco/docs/dir_201440_en.pdf (accessed 25 Sep 2015).

7 Eastwood B, Dockrell MJ, Arnott D, et al. Electronic cigarette use in young people in Great Britain 2013-2014. Public Health 2015;129:1150-6.

8 Welsh Government (2015). Exposure to secondhand smoke in cars and homes, and e-cigarette use among 10-11 year old children in Wales: CHETS Wales 2. http:// gov.wales/docs/caecd/research/2014/141203-exposure-secondhand-smokecars-ecigarette-use-among-10-11-year-olds-chets-2-main-en.pdf (accessed $25 \mathrm{Sep}$ 2015). Secondary Welsh Government (2015). Exposure to secondhand smoke in cars and homes, and e-cigarette use among 10-11 year old children in Wales: CHETS Wales 2. http://gov.wales/docs/caecd/research/2014/141203-exposuresecondhand-smoke-cars-ecigarette-use-among-10-11-year-olds-chets-2-main-en.pdf (accessed 25 Sep 2015).

9 Primack BA, Soneji S, Stoolmiller M, et al. Progression to traditional cigarette smoking after electronic cigarette use among us adolescents and young adults. JAMA Pediatr 2015;169:1018-23.

10 Vardavas Cl, Filippidis FT, Agaku IT. Determinants and prevalence of e-cigarette use throughout the European Union: a secondary analysis of 26566 youth and adults from 27 Countries. Tob Control 2015;24:442-8

11 Ooms GI, Bosdriesz JR, Portrait FR, et al. Sociodemographic differences in the use of electronic nicotine delivery systems in the European union. Nicotine Tob Res Published Online First : 4 Oct 2015. doi:10.1093/ntr/ntv215

12 European Commission. Eurobarometer 77.1, February-March 2012. GESIS Data Archive: ZA5597, dataset version 2.0.0 (2012). Brussels: TNS OPINION \& SOCIAL, 2012.

13 European Commission. Eurobarometer 82.4, November-December 2014. GESIS Data Archive: ZA5933, dataset version 5.0.0 (2014). Brussels: TNS OPINION \& SOCIAL, 2014.

14 United Nations Statistics Division. Composition of macro geographical (continental) regions, geographical sub-regions, and selected economic and other groupings. http:/l unstats.un.org/unsd/methods/m49/m49regin.htm (accessed 25 Sep 2015). Secondary United Nations Statistics Division. Composition of macro geographical (continental) regions, geographical sub-regions, and selected economic and other groupings. http:// unstats.un.org/unsd/methods/m49/m49regin.htm (accessed 25 Sep 2015).

15 European Commision. Special Eurobarometer 429. Attitudes of Europeans towards tobacco and electronic cigarettes. European Commission, 2015.

16 Filippidis FT, Gerovasili V, Vardavas Cl, et al. Determinants of use of smoking cessation aids in 27 European countries. Prev Med 2014;65:99-102.

17 Grana R, Benowitz N, Glantz SA. E-cigarettes: a scientific review. Circulation 2014;129:1972-86.

18 McNeill A, Brose LS, Calder R, et al. E-cigarettes: an evidence update. Public Health England, 2015.

19 Kaufman AR, Land S, Parascandola M, et al. Tobacco use transitions in the United States: The National Longitudinal Study of Adolescent Health. Prev med 2015;81:251-7. 
20 Reid JL, Rynard VL, Czoli CD, et al. Who is using e-cigarettes in Canada? Nationally representative data on the prevalence of e-cigarette use among Canadians. Prev Med 2015;81:180-3.

21 Bauld L, MacKintosh AM, Ford A, et al. E-cigarette uptake amongst UK youth: experimentation, but little or no regular use in nonsmokers. Nicotine Tob Res 2016;8:102-3.

22 Dutra LM, Glantz SA. Electronic cigarettes and conventional cigarette use among us adolescents: a cross-sectional study. JAMA Pediatr 2014;168:610-17.

23 Wakefield M, Morley C, Horan JK, et al. The cigarette pack as image: new evidence from tobacco industry documents. Tob Control 2002;11(suppl 1):i73-80.

24 Siu AL. U.S. Preventive Services Task Force. Behavioral and pharmacotherapy interventions for tobacco smoking cessation in adults, including pregnant women:
U.S. Preventive Services Task Force Recommendation Statement Recommendation Statement. Ann Intern Med 2015;163:622-34.

25 Brown J, Beard E, Kotz D, et al. Real-world effectiveness of e-cigarettes when used to aid smoking cessation: a cross-sectional population study. Addiction 2014; 109:1531-40.

26 Pepper JK, Emery SL, Ribisl KM, et al. How risky is it to use e-cigarettes? Smokers' beliefs about their health risks from using novel and traditional tobacco products. J Behav Med 2015;38:318-26.

27 Pepper JK, Ribisl KM, Emery SL, et al. Reasons for starting and stopping electronic cigarette use. Int J Environ Res Public Health 2014;11:10345-61.

28 McKee M, Capewell S. Electronic cigarettes: we need evidence, not opinions. Lancet 2015;386:1239. 